\title{
EFEK THERMAL FRONTUNTUK PENENTUAN DAERAH PENANGKAPAN POTENSIAL IKAN PELAGIS
}

\section{Thermal Front Effects for Determintation Potential Fishing Area of Pelagic Fish}

Oleh:

\author{
Ridwan Ariyo Nugroho ${ }^{1}$, Mega L Syamsudin ${ }^{2}$, Yuli Andriani ${ }^{2}$, dan Izza M Apriliani ${ }^{2}$ \\ ${ }^{1}$ Prodi Perikanan Fakultas Perikanan dan Ilmu Kelautan Universitas Padjadjaran \\ ${ }^{2}$ Fakultas Perikanan dan Ilmu Kelautan Universitas Padjadjaran \\ Korespondensi: rdwnariyo@gmail.com
}

\begin{abstract}
ABSTRAK
Penelitian ini bertujuan untuk mengetahui lokasi dan waktu terjadinya thermal front pada perairan Selat Bali serta pengaruhnya terhadap penentuan daerah penangkapan ikan pelagis. Metode yang digunakan adalah Single Image Edge Detection (SIED) dengan menggunakan data Suhu Permukaan Laut (SPL) yang diakses dari satelit MODIS dengan sensor Aqua (MODIS-Aqua), lokasi penangkapan tahun 2013 sampai 2015 diperoleh dari pelabuhan perikanan Pengambengan, dan arus geostropik yang diambil dari European Centre for Medium-Range Weather Forecasts (ECMWF). Identifikasi thermal front dari data citra raster SPL menggunakan algoritma SIED kemudian dianalisis secara deskriptif dengan pendekatan spasial dan temporal. Hasil penelitian menunjukan thermal front yang terbentuk bersifat sementara pada kisaran harian hingga mingguan dengan kekuatan lemah dan kuat. Thermal front terbentuk pada musim barat dimulai dari arah barat selatan Selat Bali. Musim peralihan 1 terbentuk di selatan Selat Bali. Masuk ke musim timur dan peralihan 2 terbentuknya thermal front berada pada sisi sebelah timur selatan Selat Bali. Thermal front banyak terbentuk pada musim barat dan musim timur dengan musim barat sebagai puncak. Thermal front tidak berpengaruh terhadap jumlah hasil tangkapan ikan pelagis di perairan Selat Bali. Pada daerah penangkapan ikan tidak selalu terbentuk thermal front, diduga karena lokasi wilayah Selat Bali yang terlalu kecil sehingga thermal front lebih banyak terbentuk di daerah selatan perairan Selat Bali.
\end{abstract}

Kata kunci: arus, Selat Bali, SPL, thermal front

\begin{abstract}
This study aims to determine the location and time of the occurrence of thermal fronts in the waters of the Bali Strait and their influence on the determination of pelagic fishing areas. The method used is Single Image Edge Detection (SIED) using Sea Surface Temperature (SST) data accessed from MODIS satellites with Aqua sensors (MODIS-Aqua), fishing grounds from 2013 to 2015 were obtained from the Pengambengan fishing port, and Geostropic Currents taken from the European Center for Medium-Range Weather Forecasts (ECMWF). The identification of the thermal front from the SST raster image data using the SIED algorithm is then analyzed descriptively with a spatial and temporal approach. The results showed that the thermal front formed was temporary in the range of daily to weekly with weak and strong strengths. The thermal front is formed in the west season starting from the south west of the Bali Strait. First transition season is formed in the south of the Bali Strait. Entering the east season and second transition the formation of a thermal front is on the east side of the south of the Bali Strait. Many thermal fronts are formed in the west and east seasons with the west season as the peak. Thermal front has no effect on the amount of pelagic fish caught in the waters of the Bali Strait. In fishing areas, thermal fronts are not always formed, allegedly because of the location of the
\end{abstract}


Bali Strait, which is too small so that more thermal fronts are formed in the southern waters of the Bali Strait.

Key words: Bali Strait, currents, SST, thermal front

\section{PENDAHULUAN}

Hasil tangkapan ikan yang maksimal bisa didapatkan dengan cara mengetahui mengenai informasi yang terdapat di daerah tangkapan ikan itu sendiri. Informasi mengenai daerah penangkapan ikan tersebut dapat diperoleh melalui beberapa parameter oseanografi. Parameter oseanografi merupakan faktor yang memberikan pengaruh besar terhadap variabilitas hasil tangkapan ikan. Salah satu parameter oseanografi yang memberikan pengaruh dalam menentukan daerah tangkapan ikan salah satunya adalah suhu. Dalam kehidupan ikan, parameter oseanografi yang mempunyai pengaruh sangat besar adalah suhu (Simbolon 2009). Pada daerah pertemuan antara dua massa air dengan suhu yang berbeda (thermal front) biasanya dapat dijumpai gerombolan ikan (Bakun 2006).

Suhu permukaan laut dapat digunakan untuk menyelidiki produktivitas zona frontal, daerah tersebut dapat mengindikasikan sebagai daerah potensial penangkapan ikan (Zainuddin et al. 2004; Syamsuddin et al. 2013). Thermal front dapat dijadikan sebagai indikator daerah potensial penangkapan ikan, karena terbentuknya thermal front mengandung produktivitas yang tinggi, dan merupakan feeding ground bagi jenis ikan pelagis akibat terperangkapnya zat hara dari kedua massa air yang bertemu (Robinson 1991; Sukojo 2004).

Menemukan tempat penangkapan ikan tidak hanya bergantung pada pengalaman, tetapi juga pengetahuan tentang habitat ikan. Habitat ikan terkait erat dengan nilai tertentu dari sifat oseanografi, seperti klorofil-a dan suhu permukaan laut (Semedi \& Hadiyanto 2013; Apriliani et al. 2018). Informasi mengenai parameter oseanografi yang disukai oleh ikan, dapat menghemat biaya operasional penangkapan ikan. Oleh karena itu, diperlukan penelitian lebih lanjut untuk mengetahui parameter oseanografi apa saja yang memiliki kaitan erat dalam menentukan daerah penangkapan ikan yang potensial di wilayah perairan Selat Bali khususnya fenomena thermal front.

\section{METODE PENELITIAN}

Waktu penelitian dilakukan pada bulan Maret-April tahun 2018. Lokasi penelitian berada di perairan Selat Bali dengan Pelabuhan Perikanan Nusantara (PPN) Pengambengan, Bali sebagai fishing base (Gambar 1). Tahap pertama adalah tahap pengumpulan data dan tahap kedua adalah pengolahan data. Metode survei adalah metode yang digunakan pada penelitian ini, yang meliputi analisis visual citra satelit (ex-situ) serta pengumpulan data lapangan (in-situ). Data waktu jumlah hasil tangkapan, posisi penangkapan, dan operasi penangkapan dari PPN Pengambengan merupakan data in-situ yang digunakan. Sedangkan data arus permukaan yang diperoleh dari European Centre for Medium-Range Weather Forecasts (ECMWF) serta citra suhu permukaan laut (SPL) hasil deteksi citra satelit MODIS dengan sensor Aqua (MODIS-Aqua) merupakan data $e x$-situ.

Data yang diperoleh dianalisis secara spasial dan temporal sesuai dengan wilayah dan waktu penelitian. Data input yang digunakan untuk proses deteksi thermal front yaitu data SPL hasil dari pengolahan manual ataupun otomatis. Single Image Edge Detection (SIED) merupakan algoritma yang digunakan dan telah di implementasikan menggunakan data suhu permukaan laut dari data satelit MODIS Aqua. Adapun skema prosedur pendeteksian thermal front dapat dilihat pada Gambar 2. Data pola arus dan deteksi thermal front secara spasial disatukan (overlay) dengan titik koordinat penangkapan. Hasil data tersebut kemudian dianalisis secara deskriptif untuk melihat keterkaitan antara arus, thermal front serta lokasi penangkapan ikan di perairan Selat Bali. 


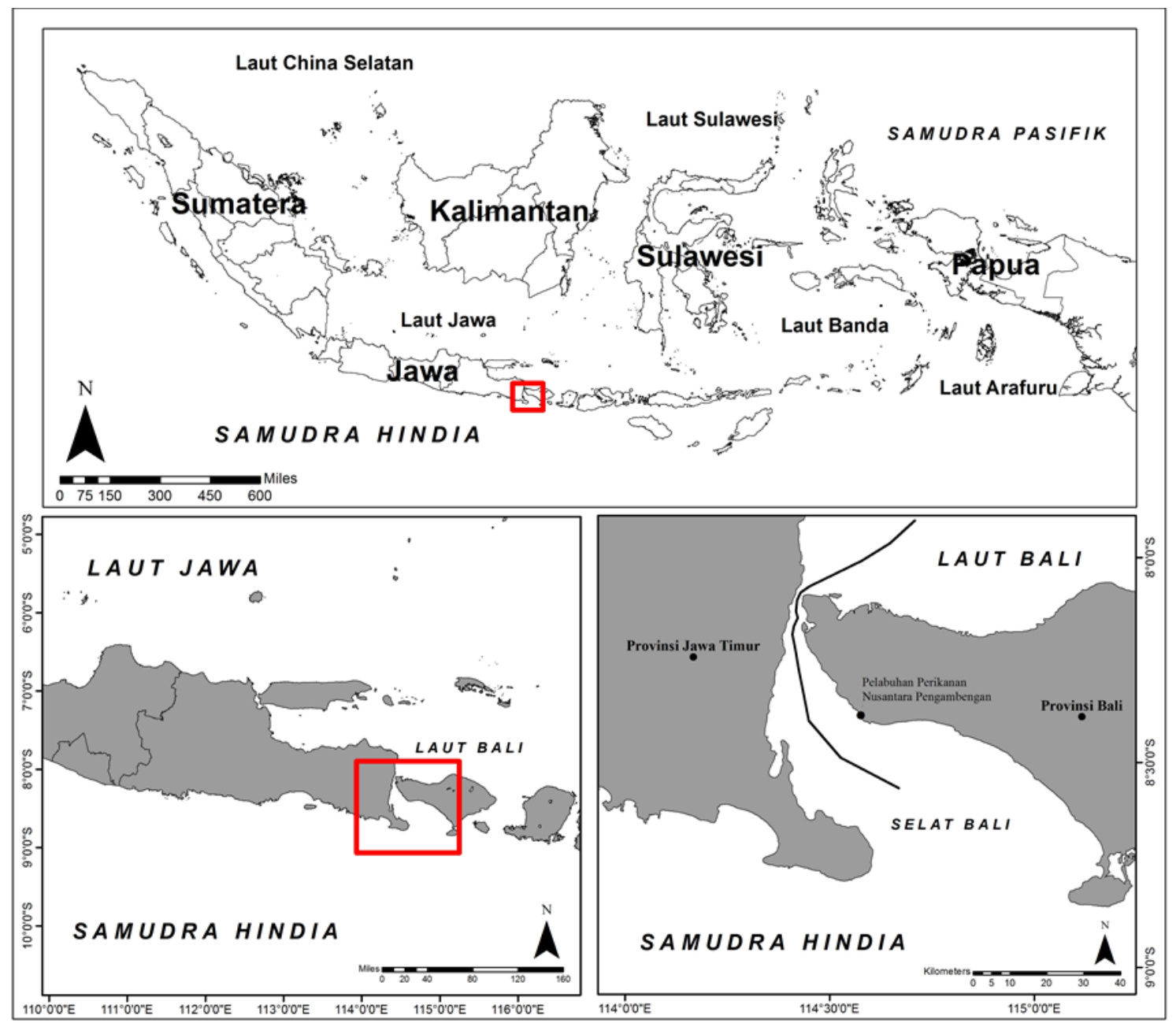

Gambar 1 Peta lokasi penelitian di perairan Selat Bali untuk dianalisis bagaimana thermal front berpengaruh terhadap hasil tangkapan ikan.

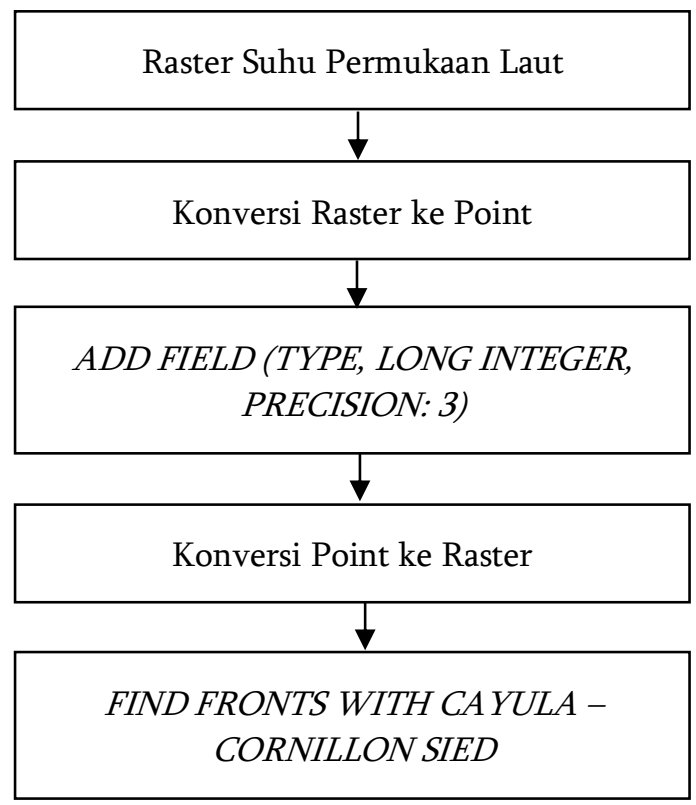

Gambar 2 Prosedur pendeteksian thermal front 


\section{HASIL DAN PEMBAHASAN}

Front yang dideteksi melalui SPL disebut thermal front. Adanya perbedaan SPL yang berbeda pada suatu perairan dan akhirnya saling bertemu, akan menyebabkan terjadinya thermal front (Bakun 2006). Pada penelitian ini deteksi thermal front dibagi menjadi dua kelompok berdasarkan pola terbentuknya. Pola terbentuknya thermal front pada perbedaan suhu permukaan laut $0,3-0,49^{\circ} \mathrm{C}$ disebut dengan weak front (thermal front yang bersifat lemah) ditandai dengan garis warna hitam, dan pola terbentuknya thermal front dengan perbedaan SPL sebesar $\geq 0,5^{\circ} \mathrm{C}$ disebut strong front (thermal front yang bersifat kuat) ditandai dengan garis berwarna merah.

Tabel 1 Jumlah dan luas area $\left(\mathrm{km}^{2}\right)$ thermal front tahun 2013-2015

\begin{tabular}{ccccc}
\hline \multirow{2}{*}{ Tahun } & Jumlah & \multicolumn{3}{c}{ Luas area $\left(\mathrm{km}^{2}\right)$} \\
\cline { 3 - 5 } & Thermal front & Jumlah & Minimum & Maksimum \\
\hline 2013 & 27 & 2766 & 4,1 & 331,8 \\
2014 & 27 & 3362,1 & 13,7 & 500,6 \\
2015 & 36 & 5466,2 & 9,7 & 390,4 \\
\hline
\end{tabular}

Thermal front yang terbentuk pada kurun waktu tahun 2013-2015 bervariasi jumlahnya (Tabel 1). Thermal front yang terbentuk paling banyak pada tahun 2015 yaitu sebanyak 36. Namun jumlah banyaknya thermal front yang terbentuk bersifat relatif, karena thermal front yang terbentuk luasan areanya tidak sama, sehingga jumlahnya banyak belum tentu memiliki luas area yang sama.

Pola terbentuknya thermal front pada tahun 2013 terdiri dari weak front (ditandai garis hitam) dan strong front (ditandai garis merah). Thermal front yang terbentuk pada tahun ini umumnya berada di wilayah selatan Selat Bali dan bersifat tidak tetap dan sementara. Hampir pada setiap bulan thermal front terbentuk selama tahun 2013. Intensitas terbentuknya thermal front cenderung bervariasi. Berdasarkan analisis visual, thermal front dengan intensitas kuat terbentuk pada musim timur dan musim barat, dengan puncak terbentuknya pada musim timur ditandai dengan garis berwarna merah yang lebih banyak (Gambar 3).

Thermal front yang terbentuk di musim timur lebih banyak terbentuk di wilayah selatan Bali. Hal ini diakibatkan oleh pergerakan arus dan sebaran SPL yang mulai stabil. Selain itu, pergerakan arah arus juga diindikasikan sebagai salah satu faktor terbentuknya thermal front yang relatif lebih tinggi pada musim timur. Memasuki musim timur arah dan kecepatan arus dominan berasal dari timur mengarah menuju barat dengan kecepatan rata-rata 0,50 sampai 4,00 m/s. Pada musim ini pergerakan arah arus mulai stabil menuju kearah barat. Arah dan kecepatan arus pada musim timur yang berasal dari timur menuju barat diduga merupakan Arus Khatulistiwa Selatan (AKS). Menurut Utamy et al (2015) AKS yang berkembang pada musim timur posisinya bisa mencapai antara $5^{\circ} \mathrm{LS}-15^{\circ} \mathrm{LS}$ dan $90^{\circ} \mathrm{BT}-$ $113^{\circ} \mathrm{BT}$. Pada musim ini kecepatan arus lebih besar pada musim lainnya, disamping AKS sedang berkembang dengan baik, terdapat pula suatu sistem arus yang membawa massa air dari Samudera Pasifik menuju Samudera Hindia melalui perairan selatan Jawa-Bali, yakni Arus Lintas Indonesia (Arlindo).

Thermal front yang terbentuk pada tahun 2014 relatif tidak terlalu kuat, terlihat dari terbentuknya thermal front dengan intensitas kuat yang lebih sedikit terbentuk dari tahun sebelumnya. Thermal front lebih banyak terbentuk pada musim peralihan 1 dan peralihan 2. Memasuki musim peralihan 1, yang terjadi pada bulan Maret, April dan Mei terlihat bahwa dari ketiga bulan tersebut terbentuknya thermal front lebih tinggi. Thermal front yang mendominasi pada musim ini adalah weak front, hal tersebut karena pada musim ini merupakan musim pergantian, sehingga memungkinkan kondisi perairan bersifat dinamis (Gambar 4).

Terlihat perbedaan pergerakan SPL pada musim peralihan 1 (barat-timur) dengan musim barat. Pada musim ini menunjukkan sebaran SPL telah bercampur antara massa air dingin dan massa air 
hangat, terjadinya perubahan pola pergerakan angin musim yang mendorong massa air permukaan diduga penyebab terjadinya peristiwa ini. Nontji (2007) menyatakan bahwa kisaran bulan April pada musim peralihan barat-timur, arus ke timur ini mulai melemah bahkan mulai berbalik arah hingga terjadi olakan-olakan (Eddies) di beberapa tempat.

Pada musim peralihan 1, secara umum pola pergerakan suhu permukaan laut yang dingin terlihat cenderung terkonsentrasi pada bagian selatan perairan Selat Bali. Mulai berpengaruhnya sistem arus musim timur yang cenderung membawa massa air bersuhu dingin diduga sebagai penyebabnya. Pengamatan secara visual mengindikasikan pada musim peralihan 1 pergerakan sebaran suhu dingin cenderung dari arah timur menuju ke barat perairan Selat Bali, namun pola pergerakan SPL ini sifatnya tidak tetap bergantung pada intensitas dan arah angin musim dominan yang mendorong massa air.

Pada tahun 2015 thermal front yang terbentuk lebih banyak dibandingkan tahun sebelumnya (Gambar 5). Dilihat dari analisis visual, hampir pada semua bulan thermal front terbentuk dengan luas yang relatif lebih besar dan intensitas yang bervariasi. Thermal front yang paling dominan pada tahun 2015 terjadi pada musim perlaihan 2. Pada musim peralihan 2, yakni waktu peralihan menuju musim barat. Pada bulan Juli, perairan Selat Bali terbentuknya thermal front lebih sedikit. Memasuki bulan Agustus intensitas terbentuknya thermal front mulai meningkat dengan intensitas kekuatannya masuk kedalam strong front. Pada bulan September paling banyak terbentuk thermal front, dengan bentuk pada umumnya adalah horizontal dan pola terbentuknya adalah strong front. Pada Bulan September banyak terbentuknya thermal front diduga akibat dari efek peralihan dari musim timur ke musim peralihan 2.

Kondisi perairan dalam rentang waktu bulan September sampai dengan bulan November memperlihatkan massa air yang lebih hangat cenderung mengalir dari bagian utara kawasan perairan Selat Bali. Hal ini diduga merupakan bagian dari Arlindo. Sebagaimana diketahui bahwa aliran massa air dari Samudera Pasifik ke Samudera Hindia melewati sebagian besar laut di Indonesia yang melewati perairan di bagian barat Sumatera. Kondisi ini diduga berpengaruh terhadap timbulnya thermal front di lokasi penelitian.

Pada musim peralihan 2 ini AKS masih berkembang cukup baik, namun kecepatan dan intensitasnya berkurang dibandingkan dengan musim timur. Memasuki musim peralihan 2, Arus Pantai Jawa (APJ) mulai berkembang di perairan selatan Bali memasuki ke arah selat namun arusnya masih relatif rendah, sehingga didesak oleh AKS yang masih berkembang pada musim ini, APJ dibelokkan kearah kanan, sehingga arah arus masih dominan menuju ke arah barat namun sudah mulai mengalami perubahan ke arah timur (Gambar 5). 


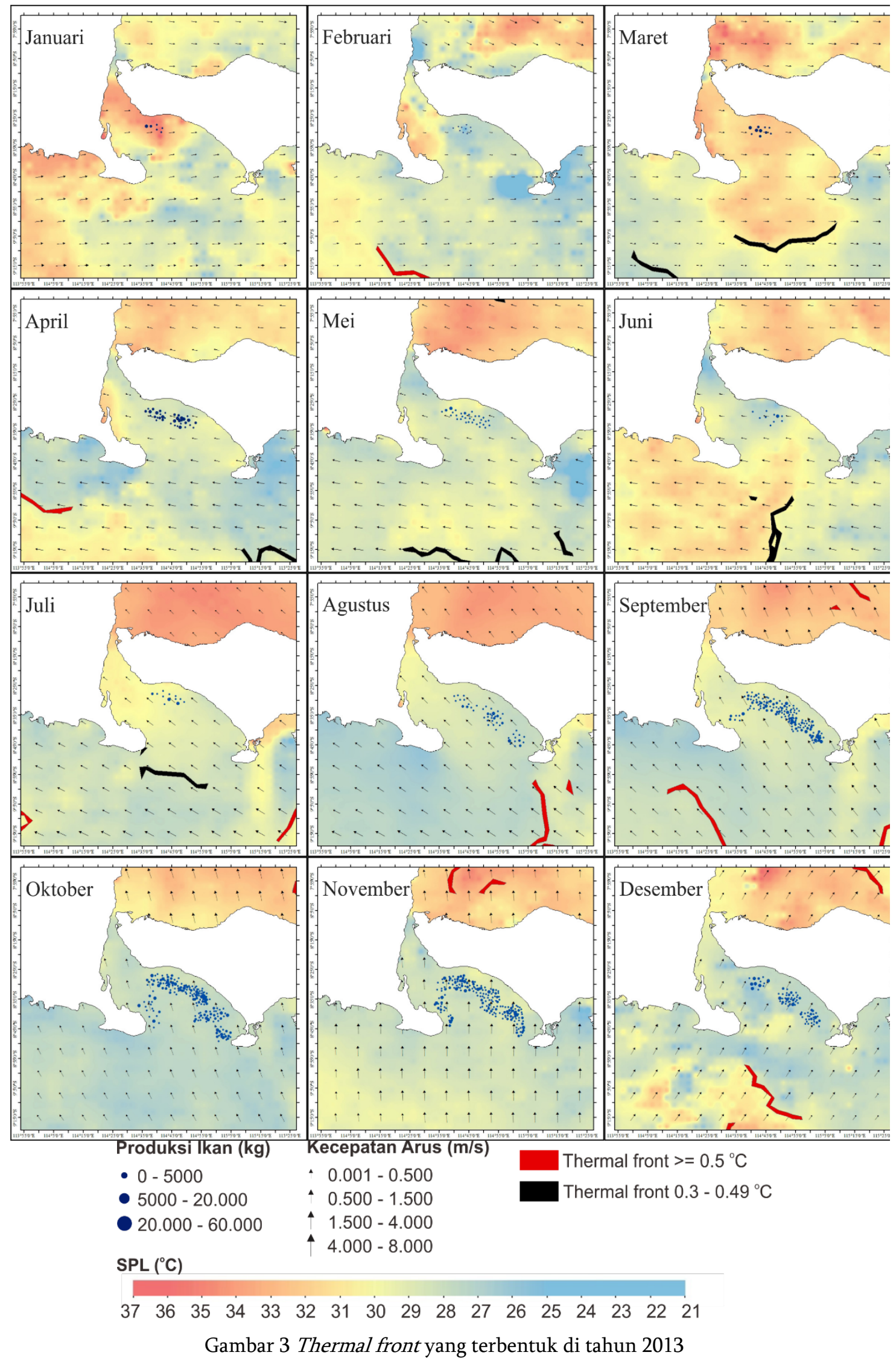




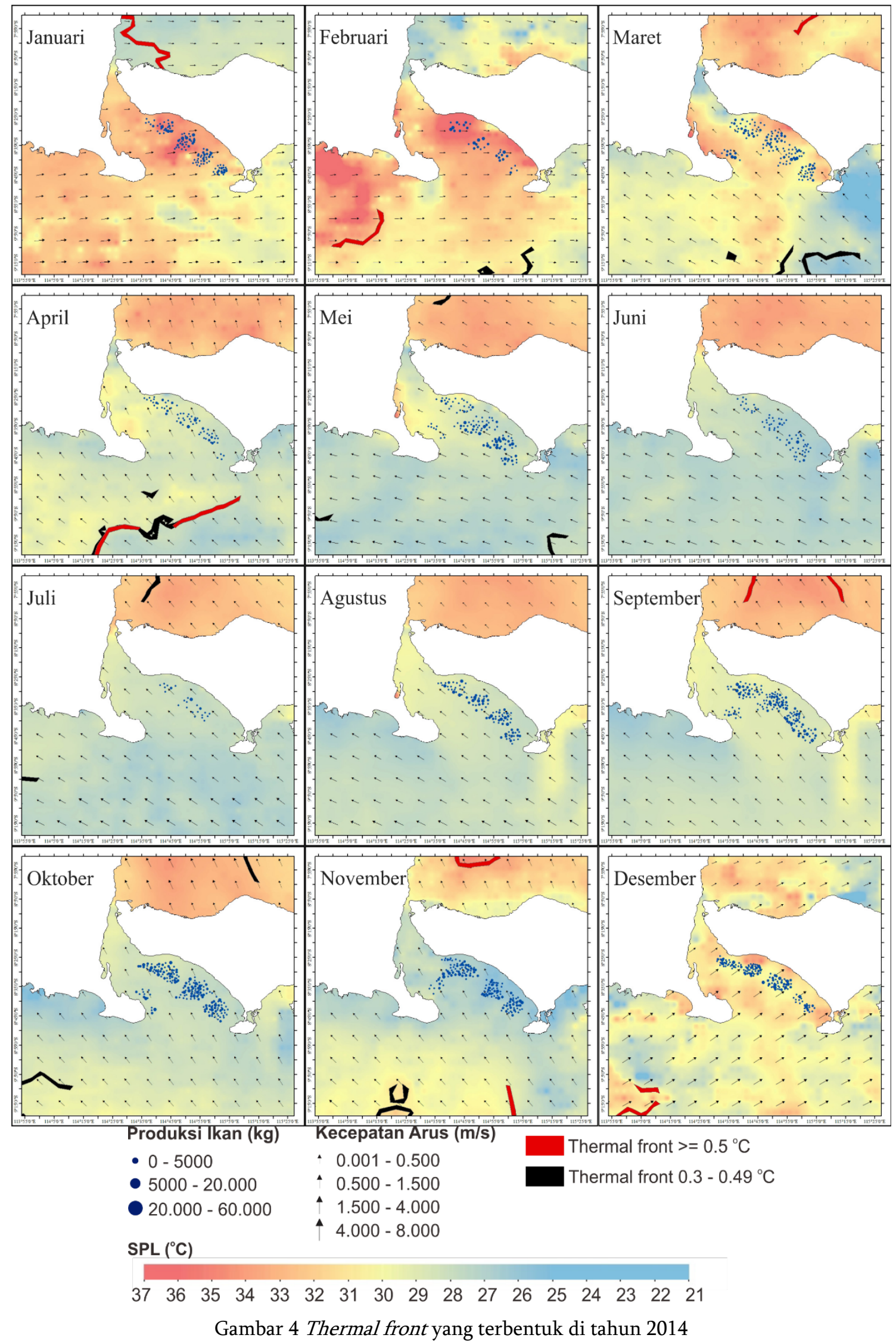




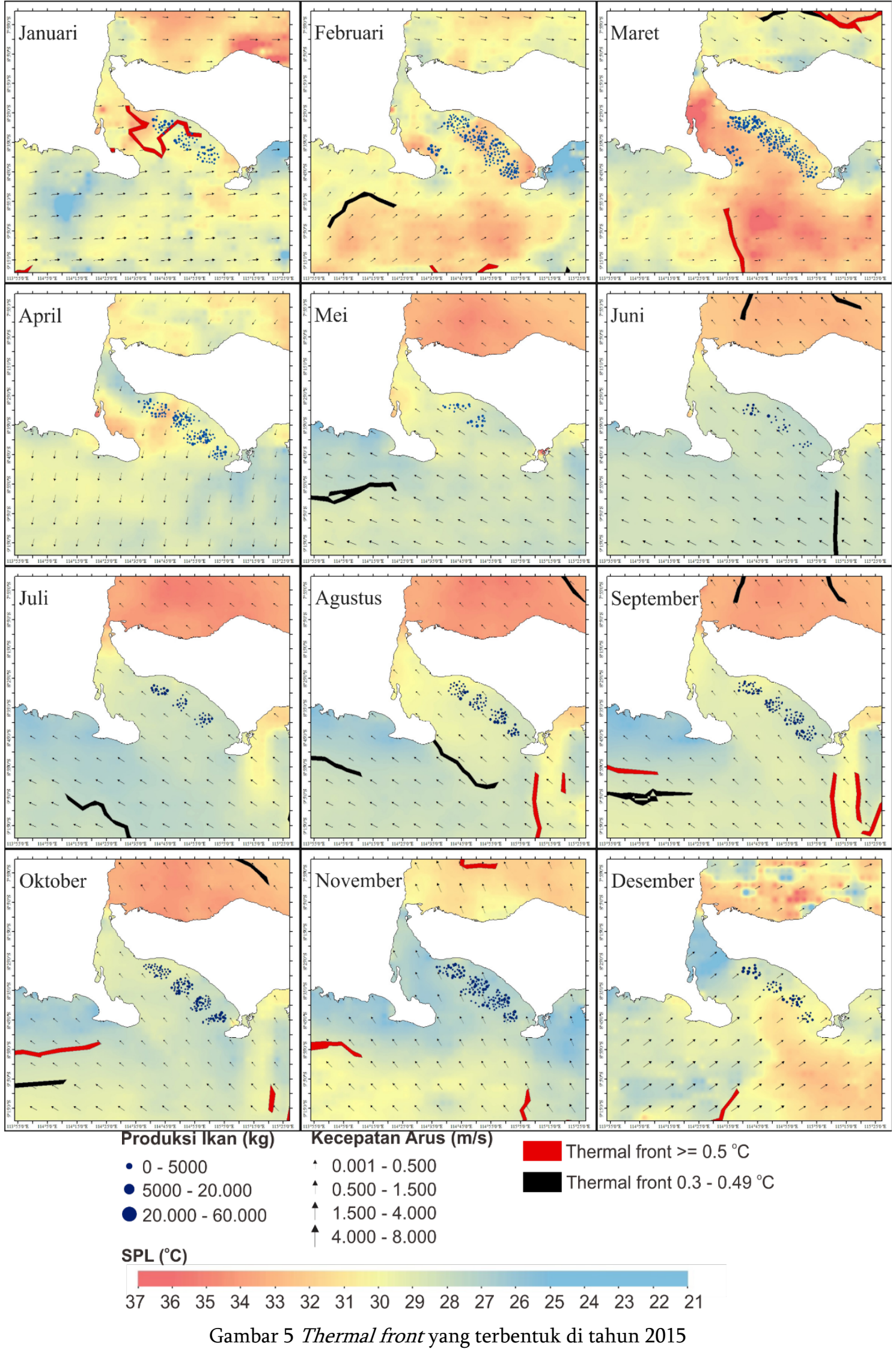


Berdasarkan hasil pengolahan data lokasi penangkapan ikan, pada umumnya lokasi penangkapan berada di sebelah barat pulau Bali. Karena thermal front yang yang terbentuk di perairan Selat Bali dan sekitarnya bersifat sementara, diduga dalam kisaran harian hingga mingguan, sehingga hanya beberapa saja yang daerah penangkapan ikan bertepatan dengan daerah terbentuknya thermal front. Analisis penangkapan ikan dengan daerah terbentuknya thermal front menggunakan nilai lokasi penangkapan dan arus permukaan.

Pada daerah penangkapan ikan ketika terjadi thermal front hasil tangkapan setara bila dibandingkan nilai rata rata hasil tangkapan tahunan, hal tersebut dapat terlihat pada bulan Januari 2015 pada daerah yang dilingkari warna hitam (Gambar 6). Tingginya hasil tangkapan diduga akibat dari terjadinya thermal front yang menyebabkan kandungan nutrien di perairan tersebut meningkat.
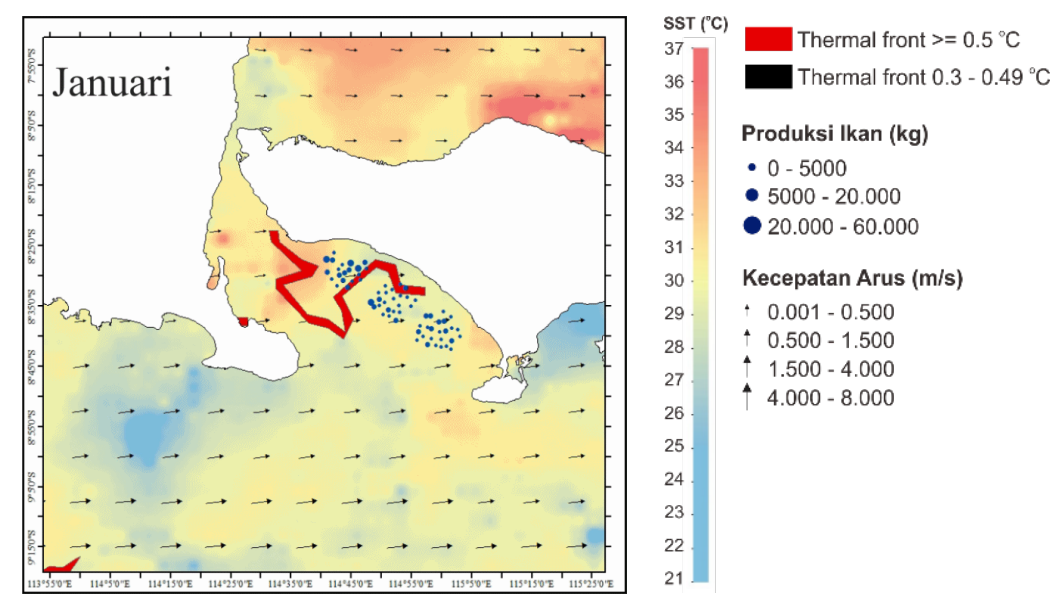

Gambar 6 Thermal front yang terbentuk di daerah penangkapan ikan lemuru

Sesuai dengan pernyataan Robinson (1991) yang menyatakan bahwa dalam hal produktivitas perairan laut thermal front penting karena cenderung membawa bersamaan massa air yang dingin serta kaya nutrien dibandingkan dengan perairan yang lebih hangat dengan unsur hara yang sedikit. Pencampuran dari peningkatan kandungan hara dan temperatur yang dihasilkan meningkatkan produktivitas plankton. Hal ini akan diikuti dengan meningkatnya stok ikan di sekitar perairan tersebut.

Terbentuknya thermal front tidak selalu bertepatan dengan lokasi penangkapan, hal tersebut terjadi pada Desember 2013, Desember 2014 dan Desember 2015 (Gambar 7) yang ditandai dengan lingkaran warna hitam. Namun terbentuknya thermal front yang tidak bertepatan dengan lokasi penangkapan ini tidak mengurangi jumlah hasil tangkapan pada waktu tersebut.

Faktor penting lainnya yang mempengaruhi produktifitas organisme di suatu perairan, adanya pencampuran oleh angin, gelombang dan arus pasang surut, lalu unsur hara akan terangkat dari dasar ke permukaan. Diperkirakan pergerakan arus permukaan yang mengandung fitoplankton serta nutrient ke wilayah penangkapan ikan di sekitar Selat Bali sehingga hasil produksi tangkapan ikan masih terbilang cukup tinggi. Hal ini sesuai dengan pernyataan Hutabarat (2000), bahwa dalam distribusi organisme arus mempunyai peranan yang sangat besar. Transportasi yang baik untuk makanan dan $\mathrm{O}_{2}$ bagi organisme adalah arus. Pantai mempunyai kecepatan arus cukup tinggi, maka penyebaran makanan dan $\mathrm{O}_{2}$ merata sehingga organisme dapat tumbuh. Menurut Wibisono (2005), arus merupakan parameter oseanografi yang sangat penting dalam lingkungan laut dan memiliki dampak secara langsung maupun tidak langsung terhadap lingkungan laut dan biota yang hidup didalamnya. 


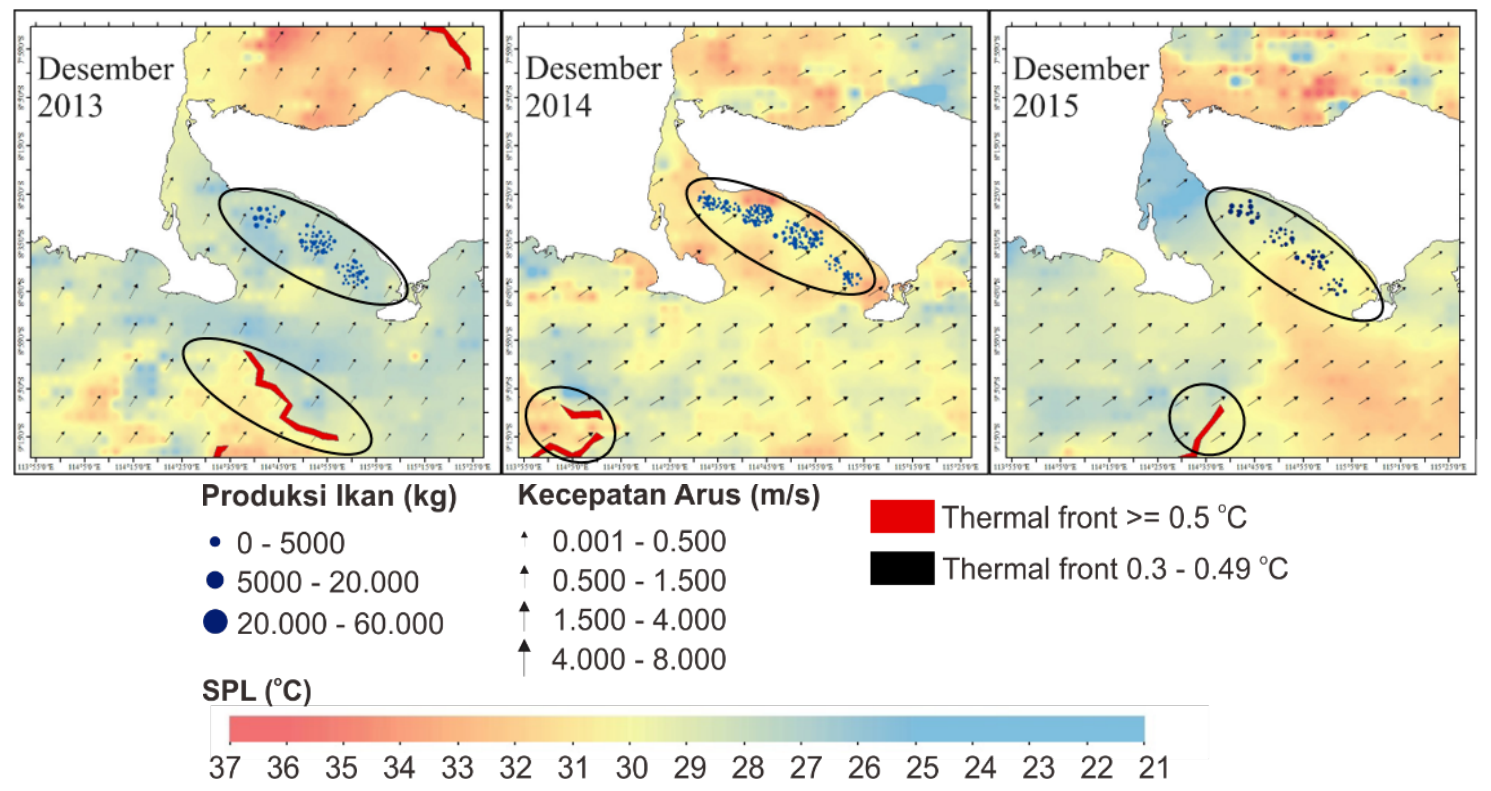

Gambar 7 Thermal front yang terbentuk di luar daerah penangkapan ikan lemuru

Secara umum jumlah hasil tangkapan yang didapatkan pada daerah terjadinya thermal front tidak selalu besar jika dibandingkan jumlah hasil tangkapan yang tidak berada pada kawasan thermal front. Diindikasikan wilayah Selat Bali yang terlalu kecil sehingga jarang terbentuk thermal front yang bertepatan dengan lokasi penangkapan ikan. Selain itu thermal front lebih banyak terjadi di daerah selatan perairan Selat Bali.

\section{KESIMPULAN DAN SARAN}

Pada umumnya thermal front yang terbentuk berada di luar perairan Selat Bali. Thermal front yang terbentuk adalah strong front dan weak front. Thermal front yang terbentuk juga bersifat sementara, diduga pada kisaran harian hingga mingguan. Thermal front terbentuk pada musim barat dimulai dari arah barat selatan Selat Bali. Musim peralihan 1 terbentuk di selatan Selat Bali. Masuk ke musim timur dan peralihan 2 terbentuknya thermal front berada pada sisi sebelah timur selatan Selat Bali. Thermal front banyak terbentuk pada musim barat dan musim timur dengan puncak terbentuknya pada musim barat. Thermal front tidak berpengaruh terhadap jumlah hasil tangkapan ikan di perairan Selat Bali. Pada daerah penangkapan ikan tidak selalu terbentuk thermal front, hal ini diduga karena lokasi wilayah Selat Bali yang terlalu kecil sehingga thermal front terlihat lebih banyak terbentuk di daerah selatan perairan Selat Bali. Berdasarkan penelitian yang telah dilakukan, diperlukan penelitian lebih lanjut mengenai hubungan thermal front dengan kelimpahan Klorofil-a di perairan Selat Bali.

\section{DAFTAR PUSTAKA}

Apriliani, I. M., Nurrahman, Y. A., Dewanti, L. P., Herawati, H. 2018. Determination of potential fishing ground for hairtail (Trichiurus sp.) fishing based on chlorophyll-a distribution and sea surface temperature in Pangandaran waters, West Java, Indonesia. AACL Bioflux. 11(4):10471054.

Bakun, A. 2006. Fronts and Eddies as Key Structures in the Habitat of Marine Fish Larvae: Opportunity, Adaptive Response and Competitive Advantage. Scienta Marina, 70S2: 105-122.

Hutabarat, S. 2000. Pengantar Oceanografi. Jakarta: Universitas Indonesia.

Nontji , A. 2007. Laut Nusantara. Jakarta: Djambatan. 
Robinson, I. S. 1991. Satelite Oceanography: An Introduction for Oceanographers and Remote Sensing Scientist. England: Ellis Horwood Ltd.

Simbolon, D. 2009. Pembentukan Daerah Penangkapan Ikan. Bogor: Institut Pertanian Bogor.

Sukojo, B. M. 2004. Pemanfaatan Teknologi Spasial untuk Inventarisasi Potensi Produk Perikanan Tangkap dalam Upaya Peningkatan Perekonomian Daerah. Pertemuan Ilmiah Tahunan 1. Surabaya: Institut Teknologi Sepuluh November.

Syamsuddin, M. L., Saitoh, S. I., Hirawake, T., Bachri, S., \& Harto, A. B. 2013. Effects Of El NinoSouthern Oscillation Events on Catches of Bigeye Tuna (Thunnus obesus) in the Eastern Indian Ocean off Java. Fishery Bulletin NOAA, 111:175 - 188, doi 10.755/FB.111.2.5.

Utamy, R. M., Purba, N. P., Pranowo, W. S., \& Suherman, H. 2015. The Pattern of South Equatorial Current and Primary Productivity in South Java Seas. 5th International Conference on Environment Science and Biotechnology (ICESB). DOI: 10.7763/IPCBEE.2015.V81.1.

Wibisono, M. S. (2005). Pengantar Ilmu Kelautan. Jakarta: Grasindo. 